\section{JAPANESE FEELING FOR PRIVACY}

\section{Takanori Tamura ${ }^{1}$}

\begin{abstract}
In this paper, we discuss the Japanese feeling of privacy. In Japan, though "Information Society" had made Japanese people aware of their privacy, Japanese like to talk about their daily life on web diaries. We presume that these tendencies towards the privacy issue were encouraged by Japanese cultural attitudes. We tested this observation (hypothesis) through content analysis of newspaper databases and web log articles using computer coding and an online survey. Through the content analysis, we found that the diffusion of information causes a sense of crisis of privacy in newspaper articles but also found people's interest in writing about their lives. Through the online survey, we clarified existence of two axes, which are privacy and wataskushi. Opposite to discussions in information ethics, and our expectations, privacy variables are not influenced by individualistic variables or independent self-image variables. There were influenced by in-between variables and violation of reciprocity variables. The concern for watakushi was influenced by both collaborative self image, reciprocity and individualism variables. That contains contradictory attitudes. This complexity is characteristic of watakushi privacy.
\end{abstract}

\footnotetext{
1 Ph.D. candidate, University of Tsukuba, Ibaraki Japanzx and lecturer, Kanto Gakuin University, Kanagawa Japan
}

\section{Introduction}

\section{Information society and the issue of privacy in Japan}

Privacy is an issue which is much discussed in the field of information ethics. In Japan, information ethics is not popular, but several scholars have started projects to introduce and develop information ethics studies.

Masahiko Mizutani introduced arguments regarding privacy and information ethics mainly in the U.S. and discussed the situation in Japan (Mizutani 2003). He introduced three different interpretations of privacy which are the "right to be let alone," the "right to self-determination," and the "right to personal information control." the "right to be let alone" is a classic concept of privacy that was first presented by lawyers in the US in 1890 . This was against invasion of privacy by yellow journalism. The "right to selfdetermination" protects freedom in one's private life. For example, this can be a right to choose language in public education or the right to an abortion, which often becomes a target of discussion (Mizutani2003:103-108). Development of computers caused a new type of privacy crisis, which is the computer matching of personal information. Before computerization, a person's name or address were not big secrets but computerization has changed the situation. With computers, birth dates and telephone numbers can be matched and can even be used to identify a high school student who needs information for college and so on. These day, we may get a telephone call from a salesperson who knows precise information about our family and this can make us feel uncomfortable. Haruhiro Kato, a sociologist in Japan, wrote that privacy became an issue because people started to have a sense of crisis 
when they accepted the "information society". The issue of privacy began to be recognized when somebody's privacy had been invaded. In Japan, there have been many accidents of cases of outflow or misuse of individual information from companies and government organizations. That evokes a sense of privacy for personal information among people.

\section{Cultural Diversity}

Based on previous literature, we would like to add some observations from the aspect of cultural diversity on information society and the issue of privacy. As discussed in the conference on Cultural Attitudes towards Technology and Communication ${ }^{2}$, acceptance of information technology reveal cultural diversities. As Makoto Nakada wrote (Nakada et al. 2004), Japanese society revealed some characteristics when they accepted information technology. Japan was westernized 150 years ago, when ideas and systems from Western countries were introduced. However, Japanese people keep manifesting another attitude in society and in human relationships. Nakada cited Keiichi Sakuta, a Japanese sociologist, and said:

...Furthermore, another criterion of value judgment, "orientation to particularism", lends itself to the way of thinking that the values of one's own particular group are more important than "universalism" (orientation to universal values such as humanism, freedom, human rights, and justice). In short, according to Sakuta, Japanese have been characterized by their tendency to think that personality, inner values, allegiance to individual reference/affiliation groups, and their relationships with people in the same reference/affiliation groups are the most important values. He also insists that the Japanese have not been motivated by

${ }^{2}$ http://www.it.murdoch.edu.au/catac/ "universalism" and "orientation to achievement" that are typical values in modern Western societies.

If this is true, Japanese society has multiple principles, which may reflect complex feelings of privacy.

In this paper, we discuss privacy issue in Japan from the cultural aspect, dealing with Japanese web diaries where private feelings are openly revealed. However, we should carefully avoid cultural essentialism, criticized by Edward W. Said (Said 1978), which claims that cultures have some solid entity like nationality or tradition. Japanese people may have some differences from others, but this is not because they have an unchangeable identity as a culture. This is because they keep changing, adapting and reproducing their cultural attitudes in their daily lives, and nothing but their interaction toward information technology is their culture. It is difficult to define the word "culture", because definition implies a kind of essentialism. However, we can tell the cultural differences between Japanese cultures and other culture because cultural diversity is a social reality.

\section{Two axes in the issue of privacy: privacy and watakushi}

There are two axes regarding the issue of privacy in Japan and the dichotomy will be used here to explain the matter simply. One is an imported concept of privacy that is closely related to the concept of public. This is a newly imported idea and partially understood by Japanese. The other is the feeling of watakushi, which is a rather indigenous feeling about private life in Japan.

The Japanese imported the word "privacy" rather late and used it as a loan word, "puraibashii". It is a new word for 
Japanese people and there is no precise equal word for privacy in the Japanese language. The word privacy first appeared in Japan as a legal issue in 1964. The Tokyo District Court recognized the right to privacy as one of the personal rights in a case concerning a novel by Mishima Yukio. A model in one of his novels, Utage no Ato, sued Mishima because he disclosed the model's personal life. This interpretation of privacy is close to the "right to be let alone." Privacy became an important issue since societies adopted nation-wide systems for citizen's information, such as the Social Security System of the US. Moreover, global ICTs like the Internet accelerate the crisis of privacy. Japan has a similar problem as well. The Internet and other information technologies have become popular and cause many of the same kinds of incidents as in other countries. When the "The National Resident Registry Network" started, there was a series of discussions in the mass media about it. However, people were not very sensitive about the issue. The "right to personal information control" became popular. It should be recognised, however, that there is some difference in the sense of privacy for mass media and the people. People care about bad effects due to outflow of information but do not think that concentration of personal information is an invasion of one's intrinsic right.

Another expression for private matters in Japanese is watakushi, which is a word older than "puraibashii." Japanese use ohyake

(公) and watakushi (私) as equivalent to "public and private". However, these two are different. In etymology, oh means big, and yake means house. Therefore, ohyake means big house. This came to mean the imperial court, the government, the nation and the society. It also means making things open and being impartial. "Public" and "government" meant almost the same until 1970-80s. Governmental activities were automatically public. They refer to construction by the government, such as bridges or dams, as Kokyo Jigyo or public enterprise. However, from 1970-80s, they started to doubt the "publicness" of public enterprise because some were useless for residents. In the same manner, they gradually began to adapt the concept "public" in their lives. Watakushi means "not ohyake", partial, secret and selfish. Watakushi things are less worthy things than ohyake things. Watakushi is not much respected and is not an individualistic idea such as that of privacy.

As mentioned above, there are two axes about public and private issues in Japan at present. The first one refers to the public and private axis and the other refers to ohyake and Watakushi axis, which are intermixed. With regard to privacy, there seems to be a privacy issue and a Watakushi issue regarding the Japanese people's feeling of privacy.

\section{Web diary}

One interesting phenomenon in the Japanese Internet scene is the popularity of web diaries. Web diaries have been popular since the advent of Japanese web sites. They are open diaries and people write anything from tiny things in their lives to serious mental struggles. However, they do not write about big secrets but instead write mostly small talk. These web sites are originally open and public, but they may believe that their web site is an extension of their private sphere. This sense of privacy can be expressed by watakushi.

Privacy usually includes some closer area to you that is yourself, your family, and your friends, etc. However, it is easier for you to talk about certain secrets with people 
who do not know you. At the same time, you can show another side of your personality to people who do not know you. A web diary may create a private world which is partially open and partially closed to people. A young woman in her twenties whom I interviewed said the following and it shows a sense of privacy as it appears in the Japanese Internet scene. She and others have a private sphere in the Internet.

I sometimes find and read my friend's diary but I do not tell her about it because I do not want to embarrass her. It seems a kind of invasion because she shows a different side of her personality from the personality that I know.

There are explanations by social psychologists concerning web diaries. Kawaura Yasushi researched why web diary authors keep writing diaries on the web (Kawaura et al. 1999). According to him, web diary authors, compared with normal diary authors, feel better about the function of self-disclosure and interpersonal communication. The higher their self-consciousness, or the more positive feedback they receive, the higher they value their diaries, and thus an increasing level of gratification and motivation to continue the web diary. Writing a web diary is an act of selfrecognition through communication with others. However, these studies do not mention what kind of cultural attitude encourages them to write web diaries. We would like to understand the motivation or tendency of Japanese that leads them to write web diaries.

Another sense of privacy may cause web site owners to prohibit free linking or the posting of a notice that "you may link to this site, but please let me know about it." There are many discussion web pages that are against this prohibition or limitation. Those in opposition claim that web pages are originally free for linking and such a limitation is ridiculous. However, according to a survey by japan.internet.com, as of $2002,90 \%$ of web site owners hope for some notice for a link to their sites and $40 \%$ are uncomfortable if somebody creates a link without prior notice given. It appears as if they may think that their web site is their private property.

It seems as if Japanese cyberspace is a kind of private sphere. This could be the reason that public discussion is not very popular in Japanese cyberspace. To approach this phenomenon, we would like to clarify Japanese attitudes towards privacy through content analysis, which refers to how they use words related to privacy and private life, and an online questionnaire survey.

\section{Hypothesis}

We observed contradictory phenomena which are: (1) increasing awareness due to information society and; (2) popularity of web diaries where they open their private lives but want regulations on linking. This is because there are two axes for privacy issue in Japan. Our hypotheses and research questions are as follows.

Hypothesis A (Privacy hypothesis): Our information society has made Japanese people aware of the concept "Privacy as the right to control one's personal information." However, people care about bad effects due to outflow of information but do not think that concentration of personal information is an invasion of intrinsic rights.

RQ1. How often do privacy-related words appear in mass media and in people's writing? 
RQ2. How much do they consider "Privacy as the right to control one's personal information" as important? What do they think about other senses of privacy?

Hypothesis B (Watakushi hypothesis): Despite the privacy hypothesis, Japanese like to talk about their daily life via web diaries because they have a sense of watakushi.

RQ3. How do they use words related to watakushi in their daily writings?

RQ4. How much do they want to talk about their private life under anonymous situations?

Hypothesis C (Cultural attitude hypothesis): Tendencies towards privacy issues were encouraged by Japanese cultural attitudes.

RQ5. Are privacy and watakushi actually different attitudes?

RQ6. What causes "privacy" and "watakushi" attitudes?

\section{Method}

We conducted two modes of research. One was content analysis by computer coding. The other was an online questionnaire survey. We conducted content analysis to answer RQ1 and RQ3 and an online survey to answer RQ2, 4, 5 and 6.

Regarding content analysis, we conducted coding of newspaper data and web log data using a computer with two aims. First, we analysed newspaper data to check time series frequencies. Second, we conducted content analysis for both web logs and newspaper articles. This was to grasp configuration and relationship of privacy and watakushi related key words.

Coding is to classify articles into groups by giving codes according to a rule. Computer coding uses a computer to classify articles. So far, especially in Japan, they have done coding by reading. Kawabata Akira, a Japanese sociologist who is developing computer coding with Japanese language, listed four advantages of coding (Kawabata et al., 2003a:165). These are: (1) It enables a large amount of data to be deal with; (2) It uses objective coding data that consists of words and which enables collaboration and check experiments; (3) It changes qualitative data into numerical data such that statistic methods can be applied; and (4) It does not depend on context of sentences. This makes researchers free from arbitrary coding. At present, it is impossible to know what a word implies and the context it was used in via computer coding (Kawabata, 2003b: 17).

With respect to the online survey, we conducted a survey to ask Internet users' opinions about privacy, web diaries and other cultural questions related to watakushi. We set questions for collaborative and independent attitudes, individualistic attitudes and in-between attitudes and reciprocity as explanatory variables. An in-between attitude is a tendency to involve relationships among group members in his or her self-concept. It has been developed as a psychological scale for in-between attitude (Yoshida 2001 : 229). We set questions for privacy, (in the English language context,) with watakushi as the dependent variable. All variables were given a five-point or fourpoint scale measure. We conducted a oneway Analysis of Variance (ANOVA) to determine which explanatory variables can effectively explain the dependent variables. 
ANOVA is a method to compare the average of numerical value groups. We posit each grade of the scale in an explanatory variable as a group and compare averages of points of dependent variables among groups to determine how much the explanatory variables affect the dependent variable.

\section{Time series analysis and Computer coding}

To understand the Japanese interpretation of privacy, we conducted two analyses with computer coding. First, we counted the frequencies of words for privacy, information, and ICT (domestic network and the Internet) in articles published in the Yomiuri Shimbun, which is the most popular national newspaper. Second, we conducted content analysis for selected newspaper articles regarding privacy and shiseikatsu(私生活). Shi means watakushi and seikatsu means life. Shiseikatsu is commonly used to express personal life.

\section{Description of data for this section}

We used the following data in this section. For calculating frequencies of the words "privacy," "information," and "ICT" in newspapers, we extracted articles that include these words in the Yomiuri Shimbun Database, from 1987 to 2004. Yomiuri Shimbun is the most popular and most widely distributed newspaper in Japan.

For content analysis, we used data from newspaper and web log articles. We prepared Yomiuri Shimbun articles that included the keyword "privacy" from newspapers in 1987 (205 articles) and in 2000 (843 articles). We prepared web log articles that included the keyword "privacy" (485 articles, September 26 November 20, 2004).

To answer RQ2, we extracted web log articles that included shiseikatsu, a Japanese word that means personal life (436 articles, September 26 - November 20, 2004). Web log data was extracted from the database of a governmental organization for technology, the Research Institute of Science and Technology for Society (RISTEX). The RISTEX database has been collecting and saving Japanese web log data every ten minutes since 2003. This system enabled us to extract time series web $\log$ data by keywords.

\section{Time series analysis - relationship between privacy and information -}

We counted words related to privacy and information in newspaper articles with a search system belonging to each newspaper database. Figure 1 shows that use of the word "privacy" increased with those of "information" and "ICT." There is a strong indication that privacy and information are directly correlated with one another given a correlation coefficient of 0.963 . This could indicate that being an information society is strongly related to a sense of privacy among people, which answers RQ1. As mentioned above, Mizutani and Kato wrote about this tendency, but this is the first empirical data to prove it. Meanwhile, we should note that this tendency is found in only one mass medium, namely, the newspaper. The other question on current usage could be found in people's usage of words. This will be tested in the following content analysis. 
Figure 1: Frequency of words in a newspaper (Yomiuri Shimbun)

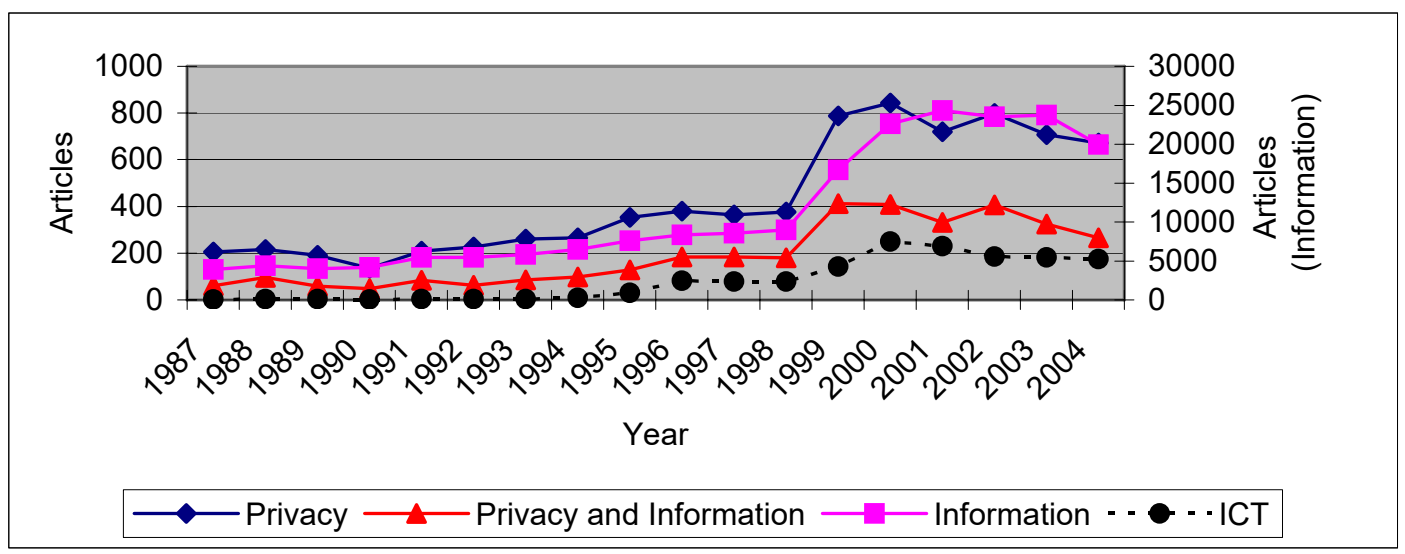

\section{Configuration of terms for privacy and private life}

\section{Coding rule}

For computer coding we used a coding rule that consisted of words. We prepared two rules for extracting the most frequently used words from newspaper and web log texts mentioned above (Tables 1 and 2). If an article included the word "information," the article got an $<$ Information $>$ code. An article may have more than one code. The process of coding makes a table filled with 1 and 0 , as indicated in table 3. Therefore, we can apply statistic analysis to the table. This table enables us to count frequency of articles in a year because articles are listed according to date. This also implies that if a certain pair of codes coexists in many articles, for example, <Privacy $>$ and $<$ Information>, these codes must be closely related or correlated. For the sake of computer coding, we used free software, KHCoder ${ }^{3}$.

\section{Table 1: Coding rule no.1}

\begin{tabular}{|l|l|}
\hline Code name & Included words \\
\hline$<$ Privacy $>$ & Privacy \\
\hline$<$ Invasion $>$ & $\begin{array}{l}\text { invasion, consideration, } \\
\text { protection, problem }\end{array}$ \\
\hline$<$ Information $>$ & Information \\
\hline$<$ Photograph $>$ & Photograph \\
\hline$<$ ICT $>$ & $\begin{array}{l}\text { the Internet, domestic } \\
\text { network }\end{array}$ \\
\hline$<$ Database $>$ & database, computer, online \\
\hline
\end{tabular}

Table 2: Coding rule no.2

\begin{tabular}{|l|l|}
\hline Code name & included words \\
\hline$<$ Private life $>$ & private life \\
\hline$<$ My self $>$ & my self \\
\hline$<$ Web diary $>$ & diary \\
\hline$<$ work $>$ & work \\
\hline$<$ talk/story $>$ & talk/story \\
\hline$<$ Life $>$ & life \\
\hline
\end{tabular}

\footnotetext{
${ }^{3}$ http://khc.sourceforge.net/
} 
Table 3: Image of coding

\begin{tabular}{|c|c|c|c|c|c|}
\hline Article & $<$ Privacy & $<$ Invasion $>$ & $<$ Information $>$ & $<$ Photograph $>$ & $<\mathrm{ICT}>$ \\
\hline 1 & 1 & 0 & 0 & 0 & 0 \\
\hline 2 & 1 & 0 & 1 & 0 & 0 \\
\hline 3 & 0 & 0 & 1 & 0 & 0 \\
\hline 4 & 1 & 0 & 1 & 0 & 0 \\
\hline 5 & 0 & 0 & 0 & 0 & 0 \\
\hline
\end{tabular}

We applied code rule No.1 to newspaper articles about privacy in 1987 because it is the oldest data and in 2000 because it is the peak of the line. After coding texts from newspapers and web logs, we calculated Jaccard coefficients ${ }^{4}$ among codes.

Figure 2 indicates relationship among codes. Thick lines mean a close relationship of codes. In the graph for 1987, we found that privacy issues occurred with invasion problems. $<$ Privacy $>$ and $<$ Invasion $>$ are related to $<$ Photograph $>$ because "gossip photo magazines" are popular. <Information $>$ did not play a big role at this time but is close to $<$ Database $>$ and $<$ Personal $>$ because online database and personal data protection were topics of discussion. In the graph for 2000, we can find a clear diamond shape relation between $<$ Privacy $>$, $<$ Personal $>$, <Information $>$, and $<$ Invasion. $>$. The lines got thicker and each code is related to each other. We found that privacy issues in a newspaper came up with increasing amounts of information. This is a newspaper framework for the privacy problem.

\footnotetext{
4 Jaccard coefficients are one measure for similarities, which is used for computer coding results because it neglects $0-0$ combinations. The table made by coding includes many $0-0$ pairs. If the measure regards $0-0$ pair as coefficient, it shows bigger co-relation coefficient than, a should be.
}

We applied the same coding rule No.1 to web $\log$ data (Figure 3). In contrast, configuration (1) indicates that web $\operatorname{logs}$ do not have such a strong framework such as those in newspapers. We used text that included the word "shiseikatsu," which is a common expression for watakushi life. We applied code rule No.2 to the text that includes the word "shiseikatsu" and found coefficients as visualized in configuration (2). <Private life $>,<$ Work $>$, and $<$ My self $>$ makes a triangle. $<$ My self $>$ is close to $<$ Talk (story) $>$ and $<$ Work $>$ is close to $<$ Life $>$. This configuration indicates ordinary Japanese people's word map for their private lives. This is not close to "the right of self-information control." "RQ3. How do they use words related to watakushi in their daily writings?" is answered by this result. We also found that their private lives are related to web diaries because Japanese like to write about their private lives on their web diaries. 
Figure 2 Comparison: configuration of terms in Yomiuri Shimbun 1987 and 2000

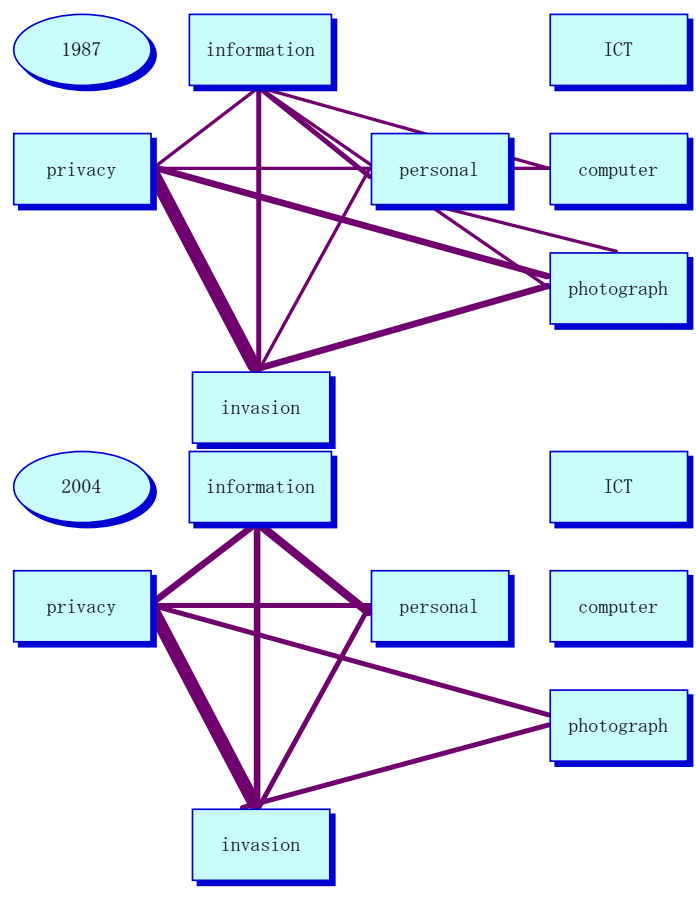

Figure 3 Comparison: configurations of terms in Web log data 2004
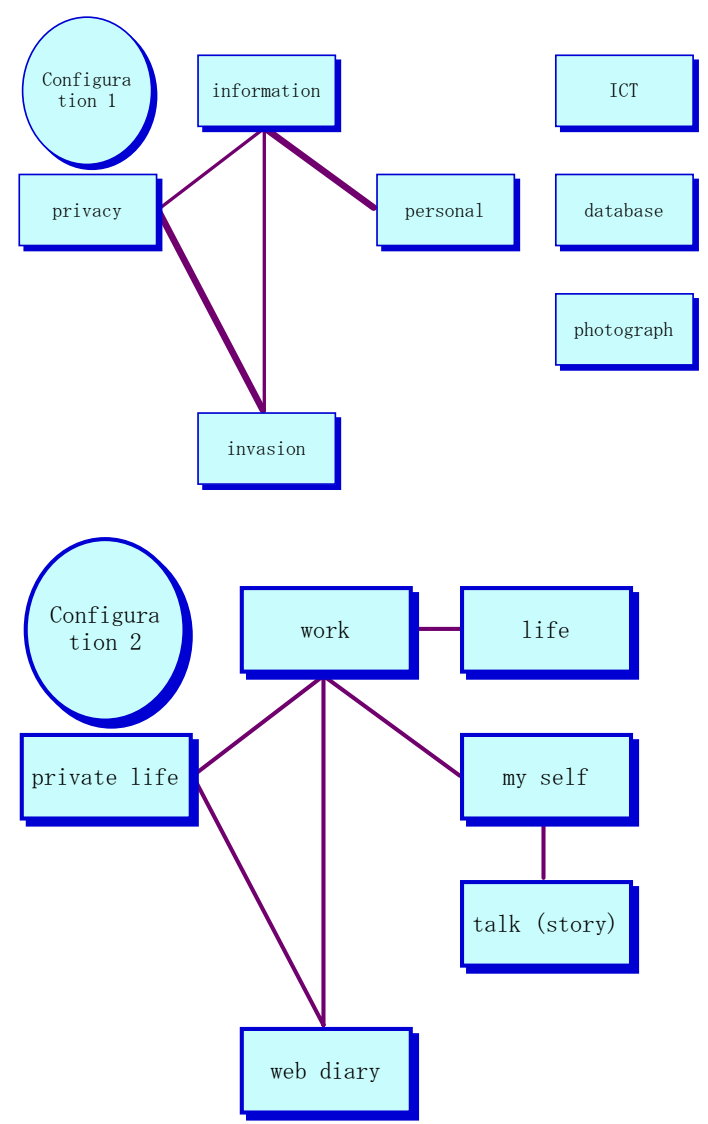

Findings of content analysis

Through this analysis, we found that diffusion of information causes a sense of crisis of privacy in newspaper articles. This is one aspect of privacy issues in Japanese society. However, word map of web log showed similar but weaker structure of words around privacy. The second analysis indicated web log users' word map, which shows their interest in writing about daily lives on web logs.

In Japanese newspapers, privacy issues are discussed as a "crisis of privacy issues" with words related to invasion, but Japanese 
people deal with cyberspace as an expanded private sphere where they can narrate their personal experiences.

\section{Online survey for privacy and watakushi}

To answer RQ2, 4, 5 and 6, we utilized the questionnaire for Internet users. Description of data and prepared questions are mentioned below.

\section{Description of data}

We distributed a questionnaire to assess people's attitudes regarding human relationship and their opinions on privacy. The Research Group on the Information Society (ReGIS) in the University of Tsukuba, represented by Professor Makoto Nakada, conducted this survey between February 14 and 19, 2005. Survey populations were 20 to 49 year-old registered survey participants selected by a Japanese research company. This survey used a quota sampling method, and ratios for gender and age were quoted from 2003 WIPJ report (Tsushin Sogo Kenkyujo 2003) and white paper for information and communication in Japan ${ }^{5}$. The valid response rate for this survey was 500 .

\section{Questions and frequencies}

Questions and frequencies of responses in the survey are described below.

\section{Dependent variables}

As dependent variables, we prepared questions about privacy and watakushi. Questions about privacy were taken from

http://www.johotsusintokei.soumu.go.jp/englis $\mathrm{h} /$ index.html an earlier survey conducted by the Cabinet Office, Government of Japan (Cabinet Office 1981, 2003) and partially developed by ReGIS. Questions about watakushi were developed by ReGIS. The figures to the right of the questions are cumulative percentages ranging from "agree" to "somewhat agree" as set out in five-point Likert scales. The order of the list is arranged according to these figures.

To get people's attitudes and opinions on privacy, we asked questions such as "We are asking you about invasion of privacy. Do you think that the following cases apply to it? Please choose one answer for each question. "Choices and frequencies are given in Table 4.

Table 2: Questions for privacy

\begin{tabular}{|l|c|}
\hline \multicolumn{1}{|c|}{ Questions } & $\%$ \\
\hline $\begin{array}{l}\text { My home address was } \\
\text { revealed to the public on the }\end{array}$ & \\
$\begin{array}{l}\text { Internet without my } \\
\text { permission. }\end{array}$ & $95.60 \%$ \\
\hline $\begin{array}{l}\text { It had been sent by the } \\
\text { advertising company etc. } \\
\text { before an individual mail } \\
\text { address was known. }\end{array}$ & $94 \%$ \\
\hline $\begin{array}{l}\text { Material concerning me had } \\
\text { been collected by some } \\
\text { name list trader etc. without } \\
\text { my knowledge. }\end{array}$ & \\
\hline $\begin{array}{l}\text { My individual information } \\
\text { had been collected without } \\
\text { my knowledge via the } \\
\text { Internet using cookies etc. }\end{array}$ & $93.40 \%$ \\
\hline $\begin{array}{l}\text { The resident registry } \\
\text { network system was used } \\
\text { by the Self Defence Force } \\
\text { to make a personal } \\
\text { solicitation list. }\end{array}$ & $91.80 \%$ \\
\hline $\begin{array}{l}\text { Lies about my family and I } \\
\text { were spread. }\end{array}$ & $88.20 \%$ \\
\hline $\begin{array}{l}\text { Spam mail is sent to my } \\
\text { address. }\end{array}$ & $87.60 \%$ \\
\hline $\begin{array}{l}\text { The contents of my diary, } \\
\text { which I published on my }\end{array}$ & $83 \%$ \\
\hline
\end{tabular}




\begin{tabular}{|c|c|}
\hline $\begin{array}{l}\text { homepage, were reprinted } \\
\text { without permission. }\end{array}$ & \\
\hline $\begin{array}{l}\text { My beliefs and opinions } \\
\text { (such as religious beliefs } \\
\text { and political parties that I } \\
\text { support) were spread. }\end{array}$ & $66.60 \%$ \\
\hline $\begin{array}{l}\text { My image was obtained } \\
\text { from a picture taken by a } \\
\text { security camera off the } \\
\text { street. }\end{array}$ & $27.40 \%$ \\
\hline
\end{tabular}

This table shows a high interest to "right to personal information control" as indicated by the top 3 answers. It answers the first part of RQ2, "How much do they consider "Privacy as the right to control one's personal information" as important?"

However, "My image was obtained from a picture taken by a security camera off the street," which is related to "right to be let alone" got a low percentage (27.40\%). That answers the second half of RQ2, "What do they think about other senses of privacy?" People do not care about collection of personal information as long as does not cause evil negative effects.

With regard to watakushi, we asked the question, "We are asking about the relationship between ohyake and watakushi. What do you think of each of the following?" Choices and frequencies are given in Table 5.

Table 3: Questions for watakushi

\begin{tabular}{|l|c|}
\hline \multicolumn{1}{|c|}{ Questions } & $\%$ \\
\hline $\begin{array}{l}\text { It is necessary to report links } \\
\text { made to my personal } \\
\text { homepage. }\end{array}$ & $74.4 \%$ \\
\hline $\begin{array}{l}\text { Personal matters (such as } \\
\text { domestic problems, etc.) } \\
\text { should not be brought in to } \\
\text { the office. }\end{array}$ & $57.8 \%$ \\
\hline $\begin{array}{l}\text { I do not want to bring work- } \\
\text { related or school-related } \\
\text { problems in to the home. }\end{array}$ & $53.0 \%$ \\
\hline
\end{tabular}

\begin{tabular}{|l|l|}
\hline $\begin{array}{l}\text { I want to hear of others' } \\
\text { personal lives if this does not } \\
\text { bother the people } \\
\text { concerned. }\end{array}$ & \\
\hline $\begin{array}{l}\text { If it is in anonymity or half } \\
\text { anonymity, you may write } \\
\text { about your daily life on the } \\
\text { Internet. }\end{array}$ & $42.2 \%$ \\
\hline $\begin{array}{l}\text { If it is in anonymity, I want } \\
\text { to speak and write about my } \\
\text { private life to someone. }\end{array}$ & $33.8 \%$ \\
\hline
\end{tabular}

We found that regulations with regard to links is strong $(74.4 \%)$ and is the top answer. Number 3 and 4 response answers "RQ4. How much do they want to talk about their private life in anonymous situations?" $30 \%$ of respondents are interested in talking about their lives and $40 \%$ are interested in hearing about others' lives.

\section{Explanatory variables}

As explanatory variables, we prepared questions about (1) independent self-image and collaborative self-image (Yamamoto 2001), (2) individualistic and in-betweenism attitudes (Yoshida 2001) and (3) reciprocity (ReGIS developed).

To ask (1) independent self-image and collaborative self-image we ask the question "How near are the six attitudes given below to your reality? Please choose the appropriate one." Choices and frequencies are given in Table 6.

\section{Table 4: Questions for independent and collaborative self-image}

\begin{tabular}{|l|l|}
\hline $\begin{array}{l}\text { *I keep an honest attitude to } \\
\text { my feelings. }\end{array}$ & $57.8 \%$ \\
\hline $\begin{array}{l}\text { *As my foremost concern, I } \\
\text { make the best of my ability. }\end{array}$ & $48.4 \%$ \\
\hline $\begin{array}{l}* * \text { I think about how I can } \\
\text { please the person around me } \\
\text { first. }\end{array}$ & $47.0 \%$ \\
\hline **I often try to match my & $38.8 \%$ \\
\hline
\end{tabular}




\begin{tabular}{|l|l|}
\hline $\begin{array}{l}\text { thoughts to other people's } \\
\text { expectation }\end{array}$ & \\
\hline $\begin{array}{l}\text { *I carry out my will even if I } \\
\text { receive opposition from } \\
\text { people who surrounds me }\end{array}$ & $36.2 \%$ \\
\hline $\begin{array}{l}* * \text { I give more priority to } \\
\text { play the role that the person } \\
\text { around me expects than to } \\
\text { show my talent. }\end{array}$ & \\
\hline
\end{tabular}

*are independent variables and

** are collaborative variables

The top two statements in the list are occupied by independent and selfaffirmating responses and the third and fourth answers represent collaborative and self-negative negative responses. Internet users in Japan are rather independent and self-affirmative, although self-negating and collaborative responses also brought in almost half. This could imply that there is a mixture of these two tendencies.

To ask (2) individualistic and in-betweenism attitudes, we ask, "How much do you agree with the following opinions? Please choose the appropriate one." Choices and frequencies are given in Table 7.

\section{Table 5: Questions for individualistic attitudes and in- between-ism attitudes}

\begin{tabular}{|l|c|}
\hline $\begin{array}{l}* * \text { Social life doesn't go well } \\
\text { if people do not help one } \\
\text { another kindly, }\end{array}$ & \\
\hline $\begin{array}{l}\text { **If you treat a person with } \\
\text { sincerity, you can understand } \\
\text { each other. }\end{array}$ & $86 \%$ \\
\hline $\begin{array}{l}\text { *You should not refrain from } \\
\text { saying what you want or } \\
\text { what you want to do. }\end{array}$ & $57.2 \%$ \\
\hline $\begin{array}{l}\text { *It goes well if you depend } \\
\text { on your decision and do not } \\
\text { rely on others' opinions }\end{array}$ & $42.4 \%$ \\
\hline
\end{tabular}

*are individualistic and **are in-betweenism variables
We can recognize superiority of inbetween-ism and relation-oriented attitudes as the top answers and negation of individualism on the bottom.

To ask (3) reciprocity, we ask, "How much do you agree with the following opinions? Please choose the appropriate one." Choices and frequencies are given in Table 8.

\section{Table 6: Questions for reciprocity}

\begin{tabular}{|c|c|}
\hline $\begin{array}{l}\text { **In today's world, goodwill } \\
\text { is often taken advantage of, } \\
\text { and there is the possibility } \\
\text { that people will look to their } \\
\text { own self-interest above that } \\
\text { of others". }\end{array}$ & $82.6 \%$ \\
\hline $\begin{array}{l}\text { *If somebody took care of } \\
\text { you or gave something to } \\
\text { you, you should give } \\
\text { something back. }\end{array}$ & $77.8 \%$ \\
\hline $\begin{array}{l}\text { *In our society, kindness } \\
\text { brings good things for both } \\
\text { ourselves and others in the } \\
\text { long run. }\end{array}$ & $59.4 \%$ \\
\hline $\begin{array}{l}* * \text { In our world, honesty } \\
\text { doesn't pay. }\end{array}$ & $49.4 \%$ \\
\hline $\begin{array}{l}\text { **In today's world, people } \\
\text { work mainly for economic } \\
\text { reasons. }\end{array}$ & $42.4 \%$ \\
\hline $\begin{array}{l}\text { *The numbers of people who } \\
\text { have a lifestyle that is } \\
\text { environmentally responsible } \\
\text { are increasing. }\end{array}$ & $28.0 \%$ \\
\hline
\end{tabular}

The top response represents violation of reciprocity. This could mean that people still have sympathy for reciprocity but it does not work well at the societal level. The second response represents importance of reciprocity. 


\section{Analysis}

To answer research questions "RQ5. Are privacy and watakushi actually different attitudes?" and "RQ6. What causes "privacy" and "watakushi" attitudes?" we conducted two analyses.

For RQ5, we conducted factor analysis. Factor analysis tries to find potential streams that influence each variable, i.e., each answer. This analysis has a hypothesis that some unseen streams are based on appeared phenomena. For example, some "scientific ability" is an unseen basis for academic scores in mathematics, physics and chemistry. We found three factors or potential streams in responses, which explained $41 \%$ of the total variance, and no correlations among the factors (Table 6). The first factor is named as "privacy factor." The second factor is named as "watakushi factor." The third factor is named "ohyake and watakushi factor." However, this was not well extracted because there were only two loaded variables.

To make a variable, which represents privacy related variables, we added the highest and the second highest loaded variable in the first factor and made a new variable. We name it "privacy variable" and gave a 10 point scale measurement.

The same is true of the second factor and we called it "watakushi variable." They are as follows:

"privacy variable" (10 point scale measurement):"My home address was revealed to the public via the Internet without my permission" (factor score ${ }^{6}$ 0.948 ) and "The resident registry network system was used for The Self
Defence Force to make a solicitation list personnel (0.803)

"watakushi variable" (10 point scale measure) : "If it is in anonymity, I want to speak and write about my private life to someone" is the variable with the highest loaded variable (0.896) and "If it is in anonymity or half anonymity, you may write about your daily life on the Internet (0.639).

${ }^{6}$ Figures in parentheses are factor scores. 
Table 7: Factor analysis : privacy and watakushi (pattern matrix)

\begin{tabular}{|l|r|r|r|}
\hline & \multicolumn{1}{|c|}{$\begin{array}{r}\text { 1 } \\
\text { privacy } \\
\text { factor }\end{array}$} & $\begin{array}{c}\text { watakushi } \\
\text { factor }\end{array}$ & $\begin{array}{c}\text { watakushi } \\
\text { and } \\
\text { factor }\end{array}$ \\
\hline $\begin{array}{l}\text { My home address was revealed to the public on the Internet } \\
\text { without my permission. }\end{array}$ & 0.948 & 0.015 & -0.036 \\
\hline $\begin{array}{l}\text { The resident registry network system was used by The Self } \\
\text { Defence Force to make a personal solicitation list. }\end{array}$ & 0.803 & -0.054 & -0.016 \\
\hline $\begin{array}{l}\text { My individual information had been collected without my } \\
\text { knowledge via the Internet using cookies etc. }\end{array}$ & 0.632 & 0.021 & 0.009 \\
\hline $\begin{array}{l}\text { Material concerning me had been collected by some name } \\
\text { list trader etc. without my knowledge. }\end{array}$ & 0.606 & -0.014 & 0.039 \\
\hline Lies about my family and I were spread. & 0.551 & -0.009 & -0.045 \\
\hline $\begin{array}{l}\text { The contents of my diary, which I published on my } \\
\text { homepage, were reprinted without permission. }\end{array}$ & 0.501 & 0.004 & -0.008 \\
\hline $\begin{array}{l}\text { It had been sent by the advertising company etc. before an } \\
\text { individual mail address was known. }\end{array}$ & 0.456 & 0.006 & -0.006 \\
\hline $\begin{array}{l}\text { My beliefs and opinions (such as religious beliefs and } \\
\text { political parties that I support) were spread. }\end{array}$ & 0.395 & 0.020 & 0.045 \\
\hline $\begin{array}{l}\text { It is necessary to report links made to my personal } \\
\text { homepage. }\end{array}$ & 0.358 & 0.074 & 0.094 \\
\hline $\begin{array}{l}\text { Personal matters (such as domestic problems, etc.) should } \\
\text { not be brought in to the office. }\end{array}$ & 0.076 & -0.036 & 0.756 \\
\hline $\begin{array}{l}\text { I want to hear of others' personal lives if this does not } \\
\text { bother the people concerned. }\end{array}$ & 0.041 & 0.596 & -0.090 \\
\hline $\begin{array}{l}\text { If it is in anonymity or half anonymity, you may write about } \\
\text { your daily life on the Internet. }\end{array}$ & 0.011 & 0.639 & -0.024 \\
\hline $\begin{array}{l}\text { If it is in anonymity, I want to speak and write about my } \\
\text { private life to someone. }\end{array}$ & -0.012 & 0.896 & 0.068 \\
\hline $\begin{array}{l}\text { I do not want to bring work-related or school-related } \\
\text { problems in to the home. }\end{array}$ & -0.026 & -0.005 & 0.655 \\
\hline
\end{tabular}

Extraction Method: Principal Axis Factoring.Rotation Method: Promax with Kaiser Normalization

To answer "RQ6. What causes "privacy" and "watakushi" attitudes?," we conducted a one-way ANOVA, between representative explanatory variables and dependent variable, i.e., privacy variables and watakushi variable. Before conducting a one-way ANOVA, we conducted a factor analysis to find representative explanatory variables. After the factor analysis, we decided a variable with the highest loaded variable was representative, as we did in the previous analysis. We found the following representative variables.

In analysis (1) independent self-image and collaborative self-image questions, we found two factors with the following variables mostly with high loaded variables. The figures in parentheses are factorloading scores. 
I carry out my will even if I receive opposition from people who surround me (0.708)

I think about how I can please the person around me first. (0.679)

In analysis of (2) individualistic attitude and in-between-ism attitude questions, we found two factors and the following variables are mostly loaded.

You should not refrain from saying what you want or what you want to do. $(0.623)$

If you treat a person with sincerity, you can understand each other. $(0.585)$

In analysis of (3) reciprocity questions, we found two factors and the following variables are mostly loaded.

In today's world, goodwill is often taken advantage of, and there is the possibility that people will look to their own self-interest above that of others. (0.750)

In our society, kindness brings good things for both others and ourselves in the long run. (0.626)

We performed a one-way ANOVA based on these described representative variables. Firstly, we tested the influence of the explanatory variables on the privacy variable.

We found that neither the individualistic variable nor the independent self image variable, which were expected to be influential according to discussions on information ethics, were influential.

However, the in-between variable and the reciprocal variable were influential on privacy valuable. In-between variable, "If you treat a person with sincerity, you can understand each other" has influence on the privacy variable. People who are more inbetween concerned are less privacy concerned (Figure 4).

\section{Figure 4: Average of privacy variable classified by degree of "If you treat a person with sincerity, you can understand each other."}

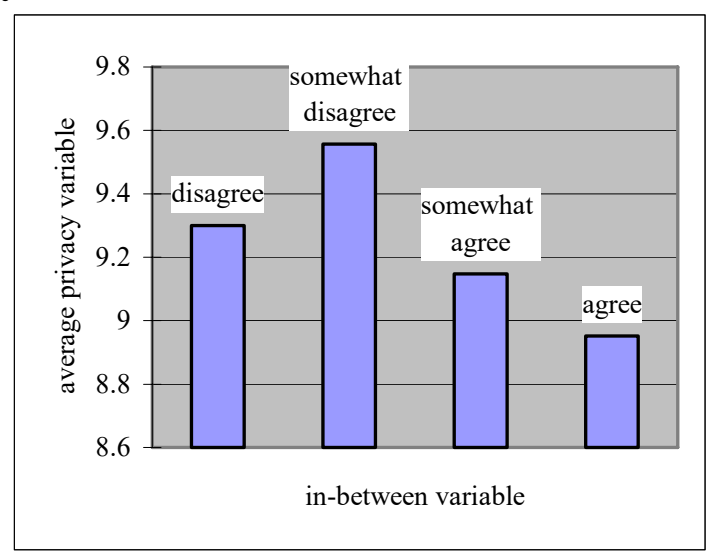

The reciprocal variable "In today's world, goodwill is often taken advantage of, and there is the possibility that people will look to their own self-interest above that of others" positively influenced the privacy variable (Figure 5). They think invasion of privacy is bad because this is against their feeling regarding reciprocity. 
Figure 5: Average of privacy variable classified by degree of "In today's world, goodwill is often taken advantage of, and there is the possibility that people will look to their own self-interest above that of others."

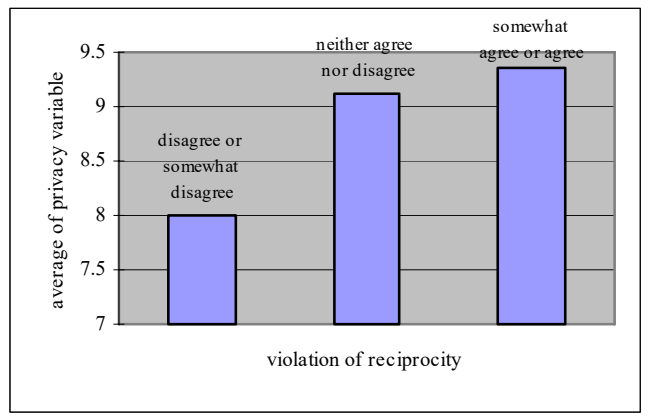

Degree of reciprocity is recollected into 3 groups because "disagree" has only one response.

We then tested the influence of the explanatory variables on the watakushi variable. A collaborative variable such as "I think about how I can please the person around me first" influenced watakushi (figure 6). The reciprocity variable "In our society, kindness brings good things for both ourselves and others in the long run"7 also influenced it (figure 7).
${ }^{7}$ Though "disagree" is the highest, difference found between somewhat agree and agree.
Figure 6: Average of watakushi variable classified by degree of "I think about how I can please the person around me the first."

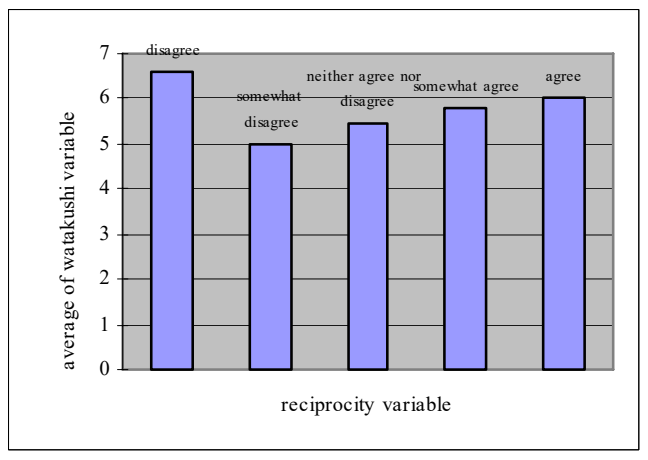

Figure 7: Average of watakushi variable classified by degree of "In our society, kindness brings good things for both ourselves and others in the long run."

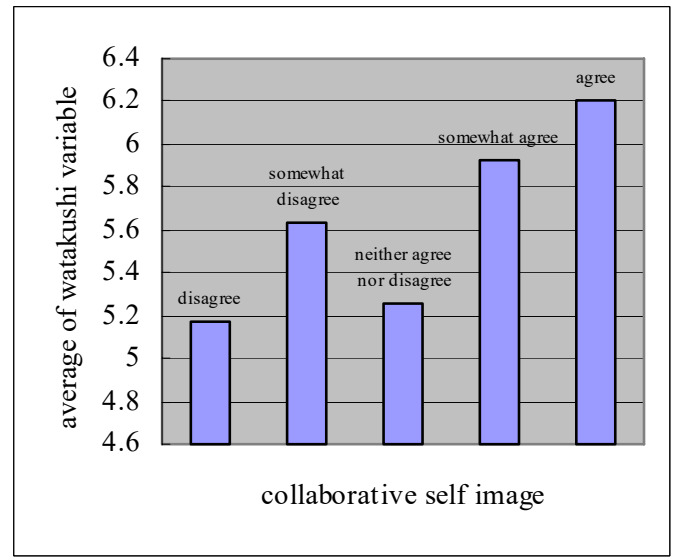

However, the individualistic variable "You should not refrain from saying what you want or what you want to do" also influences watakushi (Figure 8). Watakushi variables are mixture of these rather contradictory attitudes. 


\begin{abstract}
Figure 8: Average of wataskushi variable classified by degree of "You should not refrain from saying what you want or what you want to do."
\end{abstract}

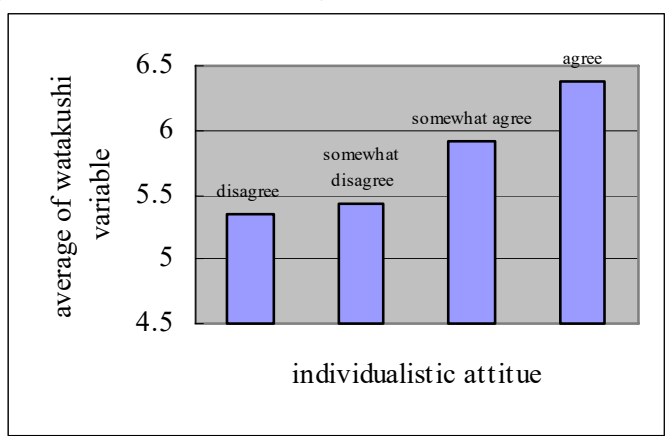

\section{Findings of online survey}

Through this analysis, we found that Japanese Internet users are concerned about the "right to personal information control" but do not care much about it as long as it does not cause negative consequences, as we saw case in the "being photographed by security cameras" got low responses. Thirty to forty percent were willing to talk and hear about their lives if it is done in anonymity. Regarding the attitude for either independence or collaboration, there were an equal number of respondents. However, the feeling of being in-between and of reciprocity was higher.

Factor analysis pointed to the privacy factor and the watakushi factor and showed that they are not correlated. We could thus prove the hypothesis of two axes in Japanese privacy.

ANOVA analysis revealed two things. Opposite to discussions in information ethics, and our expectations, privacy variables are not influenced by the individualistic variable or the independent self-image variable. They were influenced by the in-between variable and the violation of reciprocity variable.

The concern for watakushi was influenced by both collaborative self image, reciprocity and individualism variables. That contains contradictory attitudes. This complexity is characteristic of watakushi privacy.

We set two factors for Japanese feeling of privacy. That clarifies two axes and the complex feeling of Japanese regarding their feeling of privacy.

\section{Conclusion}

We found out that an: Information society makes Japanese people aware of the concept: "Privacy as the right to control one's personal information." Also, they object to invasion of their privacy because it violates reciprocity, that is, their basic moral variable for fairness. In spite of the privacy concern, Japanese like to talk about their daily life on web diaries. This is because they are caught in between collaborationism and individualism. This encourages them to seek a private sphere on the Internet. We call this private sphere, which consists of a mixture of collaborationism and individualism, as watakushi private sphere. This is reminiscent of the presentation by Chulanee Thianthai (Thianthai, 2005), which reported that young Thai people seek a private area on the Internet because they have no privacy in their home. For further studies we need to examine the situation in other Asian countries, although caution must be made in identifying common factors because of the great cultural differences among these countries.

First of all, we set two axes for privacy issues in the Japanese situation. One is the 
privacy axis and the other is the watakushi axis. We proved this by factor analysis and found unrelated factors for them. This hypothesis also clarifies a different basis of privacy from the sense in the English word and indicates a complex attitude in the watakushi axis.

The Author is grateful to Prof. Soraj Hongladarom in Chulalongkorn University who gave the author a chance for presentation in The Second Asia-Pacific Computing and Philosophy Conference (AP-CAP 2005), Prof. Charles Ess in Drury University and Prof. Rafael Capurro in Hochschule der Medien (Stuttgart) who guided the author to the privacy issue. The author is also grateful to Dr. Tomohiro Fukuhara research worker in RISTEX who permitted use of the database system, my advisor, Prof. Nakada in University of Tsukuba who allowed me to use the research data, and Prof. Kawabata Akira in Osaka University who helped in statistic analysis.

\section{References}

Cabinet office. 1981. Survey on personal information

[Online]http://www8.cao.go.jp/sur vey/s55/S56-02-55-19.html]

Cabinet office. 2003. Survey on privacy protection

[Online]http://www8.cao.go.jp/sur vey/h15/h15-kojinjouho/1.html].

Japan.internet.com research paper. $\mathrm{http}: / /$ japan.internet.com/research/ 20020319/1.html.

Kato, Haruhiro. 2003. "Denshi Network Jidaino Privacy" in Shakai Johougaku Kenkyu, 7.
Kawabata Akira et al. 2003a. "Internet ni Taisuru Hitobito no Ishiki Jiyukaito no Bunseki kara-," in Osakadaigaku Daigakuin Kenkyuka Kiyo, 29.

Kawabata Akira. 2003b. "Computer Coding no Syukyo Kenkyu heno Ouyo," in Syukyo to Syakai, 9 (separate volume).

Kawaura, Y, Yamashita, K, and Kawakami, Y. 1999. What makes people keep writing Web diaries?: Selfexpression in cyberspace. Japanese Journal of Social Psychology, 14, 133-143.

Mizutani Mashiko et al. (eds) .2003. Johorinri no Kochiku Saiensusya.

Nakada Makoto, Tamura Takanori, Leslie Tkach Kawaski and Iitaka Toshikazu .2004. "Does Old Japan Determine New Japan?" in Sudweeks F and Ess C (eds) .2004. Cultural Attitudes Towards Communication and Technology 2004, Murdoch University.

Said, Edward W. 1978. Orientalism. Pantheon Books.

Thianthai, Chulanee. 2005. "A Glance in the Life of a Computerized Generation, presentation" in The Second Asia-Pacific Computing and Philosophy Conference (APCAP 2005), Bangkok. 
Tsushin Sogo Kenkyujo. 2003. Internet no Riyodoko ni Kansuru Jittai Chousa Houkokusho (Investigation of actual conditions report concerning use trend of the Internet) Tsushin Sogo Kenkyujo.

Yamamoto, Mariko (ed). 2001. Ningnen No Naimen wo Saguru -Jiko Kojin Nai Katei - Saiensusya (Shinri Sokutei Syakudosyu 1 ).

Yoshida, Tomiji (ed). 2001. Ningen to Syakano no Tsunagari wo Toraeru - Taijin Kankei, Kachi Kan Saiensusya (Shinri Sokutei Syakudosyu 2). 